\title{
Inhibition of Endotoxin-induced Activation of Coagulation and Fibrinolysis by Pentoxifylline or by a Monoclonal Anti-tissue factor Antibody in Chimpanzees
}

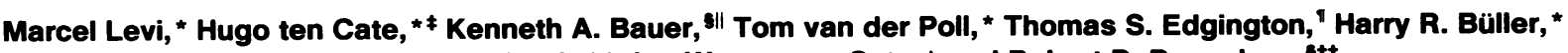 \\ Sander J. H. van Deventer, ${ }^{*}$ C. Erik Hack, * * Jan Wouter ten Cate, * and Robert D. Rosenberg ${ }^{\text {s** }}$ \\ *Center for Hemostasis, Thrombosis, Atherosclerosis and Inflammation Research and Department of Internal Medicine, Academic \\ Medical Center, 1105 AZ Amsterdam, the Netherlands; ${ }^{\ddagger}$ Slotervaart Ziekenhuis, Department of Internal Medicine, 1066 CX Amsterdam, \\ the Netherlands; ${ }^{\S}$ Beth Israel Hospital, Harvard Medical School, Boston, Massachusetts 02417; "Brockton-West Roxbury Department \\ of Veterans Affairs Medcial Center, Harvard Medical School, Boston, Massachusetts 02215; "The Scripps Research Institute, La Jolla, \\ California 92037; **Central Laboratory of the Netherlands Red Cross Blood Transfusion Service, Department of Autoimmune Diseases, \\ 1066 CX Amsterdam, the Netherlands; and ${ }^{\ddagger \pm D e p a r t m e n t ~ o f ~ B i o l o g y ~ a n d ~ W h i t a k e r ~ C o l l e g e, ~ M a s s a c h u s e t t s ~ I n s t i t u t e ~ o f ~ T e c h n o l o g y, ~}$ \\ Cambridge, Massachusetts 02139
}

\begin{abstract}
Knowledge of the pathogenetic mechanisms responsible for the activation of the coagulation system associated with endotoxemia is important for the development of improved modalities for prevention and treatment. We analyzed the appearance in plasma of TNF, IL-6, and indices of coagulation and fibrinolytic system activation in normal chimpanzees after intravenous infusion of endotoxin.

Endotoxin infusion elicited reproducible and dose-dependent elevations in serum TNF and IL-6, as well as marked increases in thrombin generation in vivo as measured by immunoassays for prothrombin activation fragment $F_{1+2}$, thrombinantithrombin III complexes, and fibrinopeptide A. Activation of the fibrinolytic mechanism was monitored with assays for plasminogen activator activity and plasmin- $\alpha_{2}$-antiplasmin complexes. To potentially intervene in the molecular pathways elicited by endotoxin, pentoxifylline, an agent that interrupts "immediate early" gene activation by monocytes, or a potent monoclonal antibody that neutralizes tissue factor-mediated initiation of coagulation, were infused shortly before endotoxin. Pentoxifylline markedly inhibited increases in the levels of TNF and IL-6, as well as the effects on coagulation and fibrinolysis. In contrast, the monoclonal antibody to tissue factor completely abrogated the augmentation in thrombin generation, but had no effect on cytokine levels or fibrinolysis.

We conclude that the endotoxin-induced activation of coagulation appears to be mediated by the tissue factor-dependent pathway, the fibrinolytic response triggered by endotoxin is not dependent on the generation of thrombin, and that the release of cytokines may be important in mediating the activation of both the coagulation and the fibrinolytic mechanisms in vivo. (J. Clin. Invest. 1994.93:114-120.) Key words: lipopolysaccharide $\bullet$ cytokine $\bullet$ tissue factor $\bullet$ thrombin $\bullet$ plasmin
\end{abstract}

This study was presented in part at the XIIIth International Congress of the International Society of Thrombosis and Haemostasis, 1-5 July 1991, Amsterdam, the Netherlands, and at the 33rd Annual Meeting of the American Society of Hematology, 2-6 December 1991, Denver, CO.

Address correspondence to Marcel Levi, M.D., Center for Hemostasis, Thrombosis, Atherosclerosis and Inflammation Research, Academic Medical Center F4-237, Meibergdreef 9, 1105 AZ Amsterdam, the Netherlands. 1993

Received for publication 3 June 1993 and in revised form 11 August

The Journal of Clinical Investigation, Inc.

Volume 93, January 1994, 114-120

\section{Introduction}

Lipopolysaccharides present in the outer membrane of Gramnegative bacteria, termed endotoxins, play a critical role in triggering the development of the clinical and laboratory manifestations of Gram-negative septicemia. Endotoxemia elicits the rapid biosynthesis and release of several cytokines including TNF, IL- 1 and IL-6 from monocytes in vitro and apparently in vivo $(1,2)$. These cytokines mediate a variety of biological effects, invoking inflammatory responses and activation of coagulation pathways. Disseminated intravascular coagulation (DIC), ${ }^{1}$ with widespread deposition of fibrin in the microvasculature commonly accompanies septic shock and is associated with the development of end-organ failure.

Knowledge regarding the pathogenesis of the coagulopathy associated with septicemia has been forthcoming to a considerable extent from studies of animals receiving lethal intravenous infusions of bacteria. In such experiments, many organ systems become severely deranged in a short period of time, and thus, clinical and laboratory observations are made at a relatively advanced stage of the disease process, oftentimes when fullblown DIC is already manifest. It is, therefore, difficult to investigate the relationships between the cytokine response and activation of coagulation, as well as the effects of various specific interventions that interfere with these processes in such models. To accomplish this, it would be desirable to use an animal model that responds to low level endotoxemia in a manner comparable to humans, and in which sensitive markers could be used to monitor coagulation mechanism activation. Such a model would be of value in evaluating potential therapeutic agents that selectively interrupt molecular pathways that may be necessary or contributory to the molecular pathogenesis of the coagulopathy in the context of endotoxemia.

We have previously established that the immunoreactivities of coagulation system zymogens and their respective activation peptides are virtually identical in humans and chimpanzees (3). In the present study, we demonstrate that endotoxin infusions result in reproducible elevation of the levels of certain cytokines, and that the activation of the coagulation and fibrinolytic pathways in chimpanzees is similar to that previously characterized for normal human volunteers $(2,4)$. To examine the role of TNF and tissue factor expression in coagulative and

1. Abbreviations used in this paper: DIC, disseminated intravascular coagulation; FIXP, Factor IX activation peptide; FpA, fibrinopeptide A; FXP, Factor X peptide; PAP, plasmin- $\alpha_{2}$-antiplasmin; TAT, thrombin-antithrombin III. 
fibrinolytic responses in vivo, we then performed experiments in which animals were pretreated with pentoxifylline or a monoclonal antibody to human tissue factor that rapidly blocks the initiation of coagulation activation by the Factor VIIa-tissue factor complex. Pharmacologic agents that elevate cellular levels of cyclic AMP such as pentoxifylline have been observed to inhibit endotoxin-induced TNF and tissue factor gene transcription by monocytes in vitro $(5,6)$. It has also been demonstrated that pentoxifylline suppresses elevations in plasma TNF levels after endotoxin infusions in vivo (7). Furthermore, bolus infusion of TNF into normal humans activates the common pathway of coagulation, probably via the extrinsic route (8). We simultaneously administered endotoxin and pentoxifylline and analyzed the subsequent activation of coagulation and fibrinolysis in comparison to the effect of endotoxin alone. To further analyze the pathway of coagulation activation, we performed another series of experiments in which we analyzed the endotoxin-induced activation of coagulation and fibrinolysis in the presence of a monoclonal antibody blocking the catalytic activity of the tissue factor-Factor VIIa complex. The present study provides new insights into the mechanisms responsible for the coagulopathic effects of endotoxin in vivo and data regarding the efficacy of specific therapeutic interventions.

\section{Methods}

Chimpanzees. Adult chimpanzees (Pan troglodytes) were housed at TNO-ITRI Primate Center (Rijswijk, the Netherlands) and New York University Laboratory for Experimental Medicine and Surgery in Primates (LEMSIP, Tuxedo, NY). The animals selected for study weighed between 35 and $70 \mathrm{~kg}$, exhibited normal kidney and liver function, and had normal routine coagulation tests (activated partial thromboplastin time and prothrombin time). The study protocols were approved by the animal health and welfare committees of the primate centers and were conducted according to the guidelines of the American Physiological Society and the Dutch Law for Animal Experiments.

Experimental protocols. After sedation with ketamine chloride, the chimpanzees were intubated and maintained under general anesthesia with nitrous oxide and halothane throughout the experiment, which lasted $5 \mathrm{~h}$. Arterial blood pressure and heart rate were continuously recorded with an automated blood pressure device and rectal temperature was measured in 15-min intervals.

Animals received U.S. Reference Escherichia coli endotoxin (Lot EC-5 from E. Coli 0113; kindly provided by Dr. D. Hochstein, Bureau of Biologics, Food and Drug Administration, Bethesda, MD) with a specific activity of $10 \mathrm{U} / \mathrm{ng}$, which was administered as a bolus injection through intravenous tubing. In dose response studies, endotoxin was given at $0.5,2,3$, or $4 \mathrm{ng} / \mathrm{kg}$ body wt to one, two, one, or four chimpanzees, respectively. In addition, two control animals received only a bolus injection of saline.

In animals receiving endotoxin and pentoxifylline $(n=3)$, chimpanzees were administered a constant intravenous infusion of $500 \mathrm{mg}$ of pentoxifylline (Hoechst, Amsterdam, the Netherlands) during a 3-h period. A bolus injection of endotoxin ( $4 \mathrm{ng} / \mathrm{kg}$ body wt) was given 30 min after the start of the pentoxifylline infusion.

An anti-tissue factor monoclonal antibody TF8-5G9, which blocks Factor VIIa-tissue factor function through inhibition of substrate access in vitro (9), was provided as purified IgG at a protein concentration of $5.5 \mathrm{mg} / \mathrm{ml}$ in phosphate buffered saline by the R. W. Johnson Pharmaceutical Research Institute (San Diego, CA). In chimpanzees receiving endotoxin and monoclonal antibody to tissue factor, $600 \mu \mathrm{g} /$ $\mathrm{kg}$ body wt of antibody was infused as a bolus just before the adminis- tration of endotoxin ( $4 \mathrm{ng} / \mathrm{kg}$ body $\mathrm{wt})(n=4)$. Based on pharmacokinetic studies in chimpanzees (data not shown) and experiments in baboons (10), the expected plasma level at $60 \mathrm{~min}$ after infusion of this dose is $\sim 10 \mu \mathrm{g} / \mathrm{kg}$. Two additional animals received the monoclonal antibody at a dose of 124 or $24 \mu \mathrm{g} / \mathrm{kg}$.

Metabolic turnover studies. The Factor X activation peptide (FXP) was purified from human Factor $X$ as outlined previously (11). The radiolabeling of FXP was carried out by the chloramine-T method of Greenwood et al. (12), using $3 \mu \mathrm{g}$ of human activation peptide and 0.5 $\mathrm{mCi}$ of carrier-free $\mathrm{Na}^{125}$ ( New England Nuclear, Boston, MA). The activation fragment was separated from free iodide by Sephadex G-10 gel filtration (Pharmacia Fine Chemicals, Piscataway, NJ). Before administration of radiolabeled peptide, animals were given $1 \mathrm{ml}$ of Lugol's solution in their drinking water, and the above treatment was continued for $3 \mathrm{~d}$ after infusion. Approximately $25 \mu \mathrm{Ci}$ of labeled peptide was infused as a bolus into a peripheral vein of chimpanzees, and serial blood samples were drawn by separate venipunctures. After centrifuging the blood samples at $1,600 \mathrm{~g}$ for $10 \mathrm{~min}$, the ${ }^{125} \mathrm{I}$ counts in 0.5 $\mathrm{ml}$ of plasma were quantified in a counting system (model 8000; Beckman Instruments Inc., Irvine, CA). The plasma protein radioactivity determinations are described as a function of time by a two-exponential curve, $C_{1} \mathrm{e}^{-\mathrm{rlt}}+C_{2} \mathrm{e}^{-\mathrm{r} 2 \mathrm{t}}$. The fractional breakdown rate, $\mathrm{K}_{\mathrm{B}}$, was calculated from $\left(C_{1} / r_{1}+C_{2} / r_{2}\right)^{-1}(13)$.

Blood collection and processing. Blood was obtained from the antecubital veins of chimpanzees using 21 -gauge butterfly needles. Samples were obtained before the endotoxin infusion and at $30,60,90,120$, 180,240 , and $300 \mathrm{~min}$ thereafter by separate venipunctures.

Samples for the determination of serum TNF and IL-6 were drawn into vacutainers. Blood for routine hematological measurements was drawn in vacutainer tubes containing $0.38 \mathrm{mmol} /$ liter EDTA (final concentration ). Blood for clotting assays (prothrombin time, activated partial thromboplastin time, and functional assays of clotting factors), measurements of thrombin-antithrombin III (TAT) complexes, and plasminogen activator activity were collected in plastic syringes containing $3.2 \%(\mathrm{wt} / \mathrm{vol})$ sodium citrate; the ratio of anticoagulant to blood was 1:9 ( vol/vol). For the prothrombin activation fragment $F_{1+2}$ and fibrinopeptide (FpA), blood was drawn into syringes containing a thrombin inhibitor, EDTA, and aprotinin (Byk-Sangtec, Dietzenbach, Germany); the ratio of anticoagulant to blood was 1:9 ( vol/vol). For assays of Factor IX activation peptide (FIXP) and FXP, blood was collected into syringes containing $38 \mathrm{mmol} /$ liter citric acid, $75 \mathrm{mmol} /$ liter sodium citrate, $136 \mathrm{mmol} /$ liter dextrose, $6 \mathrm{mmol} /$ liter EDTA, 6 $\mathrm{mmol} /$ liter adenosine, and $25 \mathrm{U} / \mathrm{ml}$ heparin; the ratio of anticoagulant to blood was 1:5. Blood for the measurement of plasmin- $\alpha_{2}$-antiplasmin (PAP) complexes, Factor XIIa-Cl inhibitor complexes, and kallikrein- $\mathrm{Cl}$ inhibitor complexes blood was obtained in siliconized vacutainer tubes containing $10 \mathrm{mmol} /$ liter EDTA and $0.05 \%$ (wt/vol) polybrene (Janssen Chimica, Beerse, Belgium) (final concentrations) to prevent in vitro complex formation.

All blood samples except those for cell counts were immediately placed in melting ice and centrifuged at $4^{\circ} \mathrm{C}$ for $20 \mathrm{~min}$ at $1,600 \mathrm{~g}$. Serum and plasma samples were stored at $-70^{\circ} \mathrm{C}$ until assayed.

Assays. TNF and IL-6 levels were determined using an immunoradiometric assay kit (IRE Medgenix, Bruxelles, Belgium) and an ELISA (14), respectively. Routine hematologic and coagulation tests were performed using standard laboratory methods. The plasma concentrations of $F_{1+2}, F X P$, and FIXP were determined by double-antibody RIA as previously described $(11,15,16)$. Plasma levels of FpA and TAT complexes were quantitated with a RIA (Byk-Sangtec) and an ELISA (Behringwerke, Marberg, Germany), respectively. Factor XIIa-Cl inhibitor complexes and kallikrein- $\mathrm{Cl}$ inhibitor complexes were determined with RIAs as previously described (17). Plasminogen activator activity was measured with an amidolytic assay (18) and PAP complexes were assayed with a RIA (19).

Statistical analysis. All values are given as mean \pm SD. Means of groups were compared with analysis of variance using the NewmanKeul's test to correct for multiple comparisons. $P<0.05$ were considered statistically significant. 
Physiologic effects of endotoxin administration. The infusion of endotoxin in chimpanzees resulted in mild and reversible physiologic reactions. At endotoxin doses $>0.5 \mathrm{ng} / \mathrm{kg}$ body wt, diastolic arterial blood pressures decreased maximally at 30 min after infusion (mean decrease $25 \mathrm{mmHg}, \pm 5.3, P<0.05$ as compared to baseline values) and rapidly returned to normal values thereafter. At all doses of endotoxin, rectal temperatures increased from $120 \mathrm{~min}$ onwards, and the largest increments were observed at endotoxin doses $>2 \mathrm{ng} / \mathrm{kg}$. The maximal increase in body temperature was $1.5^{\circ} \mathrm{C} \pm 0.4(P<0.05$ as compared to preinfusion values) at $300 \mathrm{~min}$ after the endotoxin infusion. Control chimpanzees did not receive endotoxin and showed none of the above physiologic effects. All chimpanzees recovered quickly and completely from the endotoxin infusion and anesthesia. None had evidence of long term sequelae from the experiments.

Cytokine levels after endotoxin administration. A dose-response relationship was observed between the amount of infused endotoxin and serum TNF levels. An injection of 0.5 $\mathrm{ng} / \mathrm{kg}$ body wt $(n=1)$ did not increase serum TNF concentrations, but administration of higher amounts of endotoxin resulted in peak TNF levels at $90 \mathrm{~min}$. In animals receiving 2 $\mathrm{ng} / \mathrm{kg}(n=2), 3 \mathrm{ng} / \mathrm{kg}(n=1)$, and $4 \mathrm{ng} / \mathrm{kg}(n=4)$, the maximal levels were $38.8,97.4$, and $271 \mathrm{ng} /$ liter \pm 25.7 , respectively (Fig. 1). Serum TNF was less than the detection limit of the assay ( $5 \mathrm{ng} /$ liter) in control chimpanzees receiving saline.

Endotoxin also elicited dose-dependent progressive elevations in serum IL-6. Peak IL-6 levels were observed at $120 \mathrm{~min}$ after infusion rather than at $90 \mathrm{~min}$, as was seen for TNF, and were $40.9 \mathrm{ng} /$ liter after $2 \mathrm{ng} / \mathrm{kg}$ of endotoxin $(n=2), 93.4$ $\mathrm{ng} /$ liter after $3 \mathrm{ng} / \mathrm{kg}(n=1)$, and $225.0 \mathrm{ng} / \mathrm{liter} \pm 42.7$ after 4 $\mathrm{ng} / \mathrm{kg}(n=4)$. IL-6 returned to baseline levels by $240 \mathrm{~min}$. The levels of TNF and IL-6 after an endotoxin dose of $4 \mathrm{ng} / \mathrm{kg}$ are shown in Fig. 1.

Activation of coagulation and fibrinolysis by endotoxin. After infusion of endotoxin, no significant changes were observed in the prothrombin time, activated partial thromboplastin time, platelet count, or the plasma levels of coagulation Factors VII, X, prothrombin, and fibrinogen, as compared to baseline measurements (data not shown). In contrast, a significant acceleration in thrombin generation as monitored by assays for $\mathrm{F}_{1+2}$ and TAT complex occurred in animals receiving $\geq 2 \mathrm{ng} / \mathrm{kg}$ body wt of endotoxin. Definitive elevations in these two markers, however, were not evident until $180 \mathrm{~min}$ after endotoxin infusion, and maximal levels were observed at 240 min. In animals receiving $2(n=2), 3(n=1)$, and $4 \mathrm{ng} / \mathrm{kg}$ endotoxin $(n=4)$, the levels of $F_{1+2}$ and TAT complex at 240 min were $2.0 \mathrm{nmol} /$ liter and $14 \mathrm{ng} / \mathrm{ml}, 2.68 \mathrm{nmol} /$ liter and $23.1 \mathrm{ng} / \mathrm{ml}$, and $5.9 \pm 1.1$ and $71.9 \mathrm{ng} / \mathrm{ml} \pm 16.7$, respectively (Fig. 2). The onset of accelerated thrombin generation was also associated with significantly increased fibrinogen conversion as demonstrated by concordant increments in FpA levels with the highest levels observed at $240 \mathrm{~min}$. In animals receiving 2 ( $n$ $=2), 3,(n=1)$, and $4 \mathrm{ng} / \mathrm{kg}$ endotoxin $(n=4)$, FpA levels at $240 \mathrm{~min}$ were $14.4,22.9$, and $39.7 \mathrm{nmol} /$ liter \pm 9.4 , respectively (Fig. 2).

The infusion of endotoxin did not result in measurably increased Factor IX or Factor X activation as reflected by the

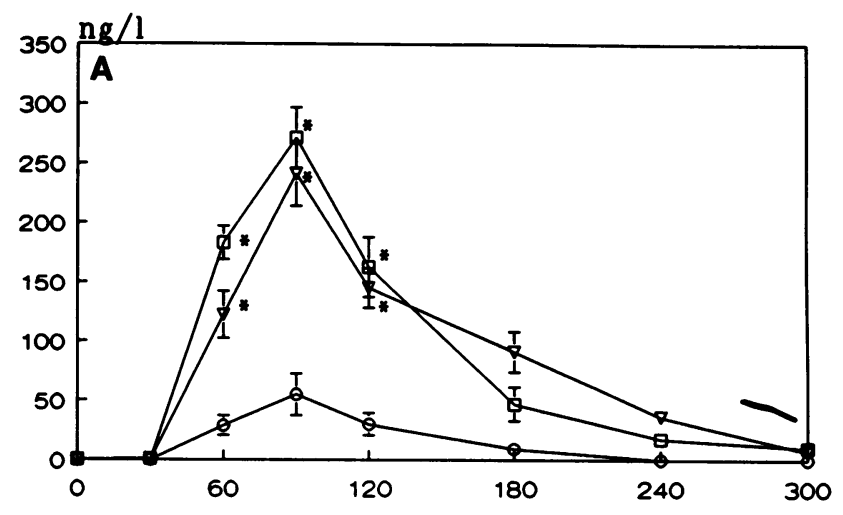

interleukin -6

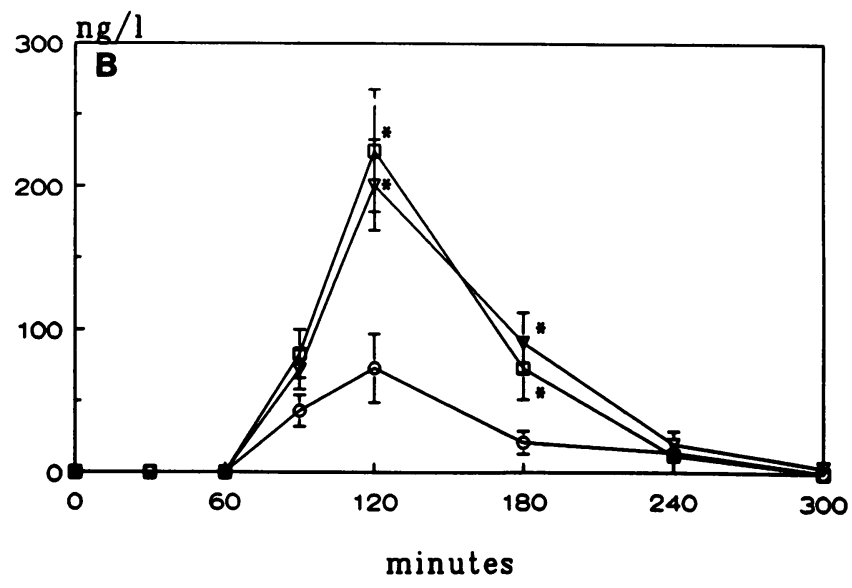

Figure 1. Serum levels of TNF $(A)$ and IL-6 $(B)$ after the intravenous administration of endotoxin $(4 \mathrm{ng} / \mathrm{kg})$. The results of the intravenous administration of endotoxin alone $(\square)$ are compared with the results of the combined infusion of endotoxin $(4 \mathrm{ng} / \mathrm{kg})$ and pentoxifylline $(O)$ or of the combined infusion of endotoxin $(4 \mathrm{ng} / \mathrm{kg})$ and 600 $\mu \mathrm{g} / \mathrm{kg}$ anti-tissue factor monoclonal antibody $(\nabla)$. Mean values and $\mathrm{SD}$ are given, statistical significance $(P<0.05)$ as compared to the chimpanzees receiving endotoxin alone is indicated $\left({ }^{*}\right)$.

absence of significant changes in the plasma levels of FIXP and FXP, respectively (data not shown). Markers of contact pathway activation (i.e., Factor XIIa-C1 inhibitor complexes, kallikrein-Cl inhibitor complexes, and FIXP) did not increase in any of the animals (data not shown).

As endotoxin is known to induce tissue factor expression by vascular endothelial cells (20-22) as well as monocytes in vitro (23), we might have anticipated elevations in plasma levels of FXP after the infusion of these agonists. To determine whether the infusion of endotoxin alters the clearance of FXP from the circulation, two chimpanzees were infused with ${ }^{125} \mathrm{I}-\mathrm{FXP}$ followed by a bolus of either endotoxin ( $4 \mathrm{ng} / \mathrm{kg}$ body wt) or saline (see Methods). The fractional disappearance rate of 
$F 1+2$

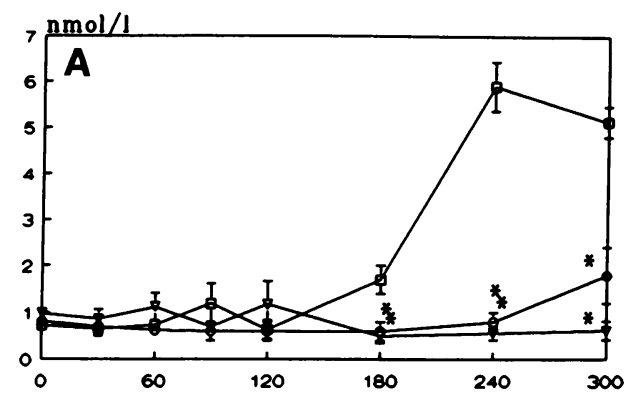

TAT complexes

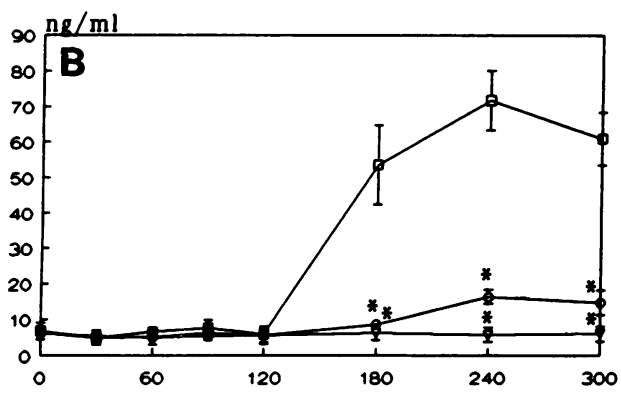

Fibrinopeptide A

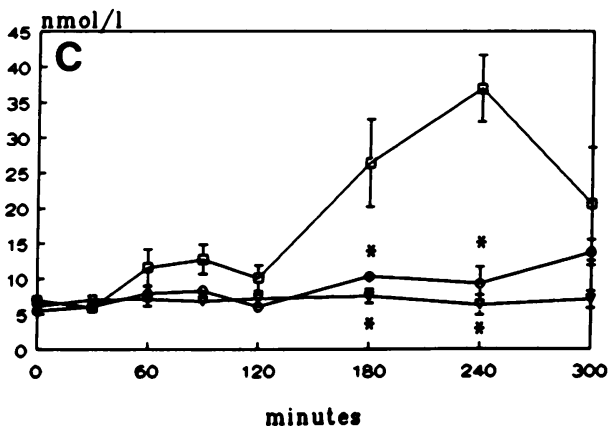

Figure 2. Effects of endotoxin administration on thrombin generation and fibrinogen to fibrin conversion, as reflected by plasma levels of prothrombin activation fragment $\mathrm{F}_{1+2}(A)$, TAT complexes $(B)$, and fibrinopeptide $\mathrm{A}(C)$. Results are shown of experiments in which endotoxin $(4 \mathrm{ng} / \mathrm{kg}$ ) was given alone $(\square)$ or in combination with 500 mg pentoxifylline $(O)$ or $600 \mu \mathrm{g} / \mathrm{kg}$ anti-tissue factor monoclonal antibody $(\nabla)$. Mean values and SD are given, statistical significance $(P<0.05)$ as compared to administration of endotoxin alone is indicated $\left({ }^{*}\right)$.

FXP was $0.86 \mathrm{hr}^{-1}$ in the presence of endotoxin, as compared to $0.60 \mathrm{hr}^{-1}$ in the absence of endotoxin.

Activation of the fibrinolytic mechanism preceded the coagulative response. Incremental increases of plasminogen activator activity and PAP complexes occurred relatively early after endotoxin administration reaching a peak at $120 \mathrm{~min}$, and declined rapidly thereafter (Fig. 3). However, the fibrinolytic markers did not increase in a clear dose-dependent fashion. After $2 \mathrm{ng} / \mathrm{kg}$ body wt of endotoxin, a significant increase in plasminogen activation and plasmin generation was observed, which did not differ significantly from that observed with higher doses of endotoxin (i.e., 3 or $4 \mathrm{ng} / \mathrm{kg}$ ). At $120 \mathrm{~min}$ after the infusion of $4 \mathrm{ng} / \mathrm{kg}$ endotoxin, the plasma levels of plasminogen activator activity increased 3.5 -fold, and the mean plasma level of PAP complexes increased to $25 \mathrm{nmol} /$ liter \pm 8.1 from $7 \mathrm{nM} \pm 2.0$ at baseline.

Pentoxifylline experiments. The suppressive effect of the xanthine oxidase inhibitor pentoxifylline on endotoxin-induced elevations in serum TNF and IL-6 concentrations is illustrated in Fig. 1. In contrast to the marked increase in the levels of these cytokines after the infusion of $4 \mathrm{ng} / \mathrm{kg}$ body wt

\section{plasminogen activator activity}

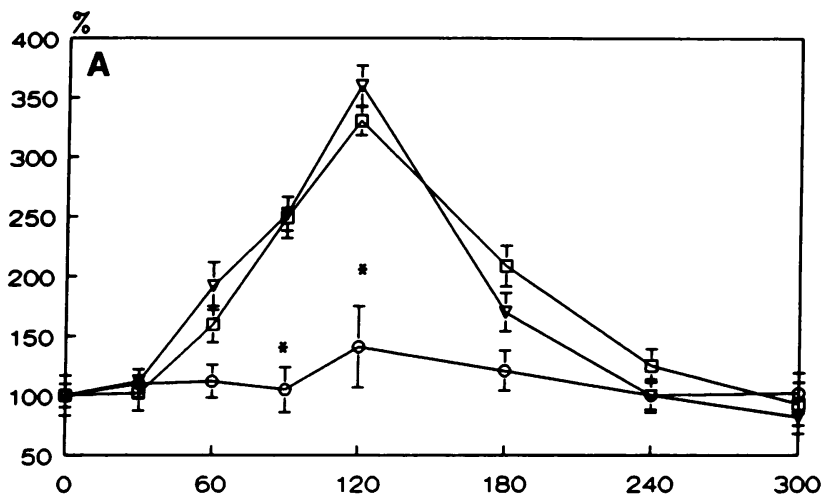

\section{PAP complexes}

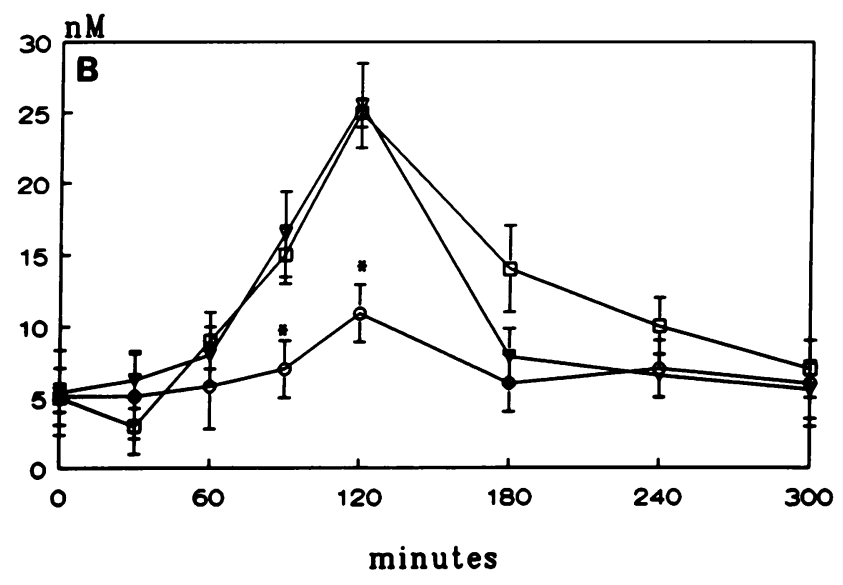

Figure 3. Activation of the fibrinolytic system after intravenous administration of endotoxin, as illustrated by plasminogen activator activity $(A)$ and plasmin- $\alpha 2$-antiplasmin complexes. Results are shown of experiments in which endotoxin $(4 \mathrm{ng} / \mathrm{kg}$ ) was given alone $(\square)$ or in combination with $500 \mathrm{mg}$ pentoxifylline $(O)$ or $600 \mu \mathrm{g} / \mathrm{kg}$ anti-tissue factor monoclonal antibody $(\nabla)$. Mean values and SD are given, statistical significance $(P<0.05)$ as compared to administration of endotoxin alone is indicated $\left({ }^{*}\right)$. 
endotoxin alone, the administration of this dose of endotoxin to three animals receiving intravenous pentoxifylline resulted in considerable attenuation of the increase in serum TNF and IL-6 (at $90 \mathrm{~min}$, mean TNF level $=54.8 \mathrm{ng} /$ liter \pm 39.3 vs 271 $\mathrm{ng} /$ liter \pm 25.7 in animals receiving endotoxin alone, $P<0.05$; mean IL-6 level $=114.2 \mathrm{ng} / \mathrm{ml} \pm 34.5$ vs $225.0 \mathrm{ng} /$ liter \pm 42.7 in animals receiving endotoxin alone, $P<0.05$ ). These observations demonstrate that pentoxifylline is able to inhibit these cytokine responses to endotoxemia in vivo.

The administration of pentoxifylline along with $4 \mathrm{ng} / \mathrm{kg}$ body wt endotoxin also had a significant effect on thrombin generation (Fig. 2). At the 240 min time point, the mean plasma levels of $F_{1+2}$, TAT complex, and FpA were suppressed to $1.8 \mathrm{nmol} /$ liter $\pm 1.1,14.7 \mathrm{ng} / \mathrm{ml} \pm 2.5$, and $18.2 \mathrm{nmol} /$ liter \pm 7.1 , as compared to $5.9 \mathrm{nmol} /$ liter $\pm 1.1,71.9 \mathrm{ng} /$ $\mathrm{ml} \pm 16.7$, and $39.7 \mathrm{nmol} /$ liter \pm 9.4 , respectively, in chimpanzees receiving endotoxin alone, $P<0.05$ ). Activation of the fibrinolytic mechanism by endotoxin was also inhibited by pentoxifylline infusions (Fig. 3). At $240 \mathrm{~min}$, the mean plasminogen activator activity and PAP complex levels were $141 \%$ of normal \pm 34 and $8.9 \mathrm{nmol} /$ liter \pm 2.1 , as compared to $330 \% \pm 49$ and $25.0 \mathrm{nmol} /$ liter \pm 8.1 , respectively, after endotoxin alone $(P<0.05)$.

Anti-tissue factor antibody experiments. The role of induced cellular expression of tissue factor in endotoxin-elicited activation of coagulation was investigated by administering a rapidly neutralizing monoclonal antibody to tissue factor (TF8-5G9) at a dose of $600 \mu \mathrm{g} / \mathrm{kg}$ body wt immediately before infusing $4 \mathrm{ng} / \mathrm{kg}$ body wt endotoxin. In four chimpanzees, the elevations of serum TNF and IL-6 were comparable to those observed for endotoxin alone (Fig. 1). The effect of administration of tissue factor antibody on coagulation activation after endotoxin infusions is illustrated in Fig. 2. The augmented thrombin generation as measured by the $F_{1+2}$, TAT complex, and $\mathrm{FpA}$ assay that normally follows endotoxin administration was completely inhibited throughout the 5-h period of the experiment $(P<0.01)$. In experiments in which a 5 - or 25 -fold lower dose of the anti-tissue factor monoclonal antibody ( 120 and $24 \mu \mathrm{g} / \mathrm{kg}$, respectively) was administered before infusing 4 $\mathrm{ng} / \mathrm{kg}$ endotoxin, no increase in the plasma levels of $\mathrm{F}_{1+2}$, TAT complexes, or FpA was observed (data not shown).

Despite the complete inhibition of endotoxin-induced thrombin generation by antibody TF8-5G9, the activation of the fibrinolytic system was not inhibited. The effect of the combined administration of endotoxin and anti-tissue factor monoclonal antibody on plasminogen activator activity and plasma levels of PAP complexes is shown in Fig. 3. At $120 \mathrm{~min}$ after administering endotoxin, the plasma level of plasminogen activator activity and PAP complexes had increased to an extent similar to that elicited by endotoxin alone.

\section{Discussion}

To delineate the mechanisms that activate the coagulation and fibrinolytic mechanisms in patients with Gram-negative septicemia, we have developed a model of endotoxemia in chimpanzees. Endotoxemia results in reproducible and dose-dependent elevations in serum levels of TNF and IL-6, as well as marked acceleration of thrombin generation in vivo, the latter assessed by quantitation of plasma $F_{1+2}$, TAT complexes, and FpA. Significant activation of the fibrinolytic mechanism was detected with assays for plasminogen activator activity and PAP complexes. These responses are comparable to those previously reported for normal volunteers receiving similar doses of endotoxin intravenously, thereby supporting the relevance of the chimpanzee model to human disease $(1,2,4)$.

We have now adopted this animal model to assess potential avenues of intervention with agents that may interfere with the pathogenetic pathways associated with sepsis. Animals were administered pentoxifylline, a xanthine oxidase inhibitor that inhibits "immediate early" cellular gene activation by monocytes. Also, a monoclonal antibody that rapidly neutralizes tissue factor activity was evaluated in this model.

Pentoxifylline, infused continuously starting $30 \mathrm{~min}$ before endotoxin, markedly inhibited increases in the levels of TNF and IL-6, as well as the effects on markers of activation of coagulation and fibrinolysis. In contrast, the monoclonal antibody to tissue factor abrogated the acceleration of thrombin generation (as indicated by unchanged levels of $F_{1+2}$ and TAT complexes), but had no effect on cytokine levels or fibrinolysis.

While our results with the anti-tissue factor monoclonal antibody clearly indicate that tissue factor is responsible for endotoxin-elicited initiation of the coagulation pathway culminating in thrombin generation in vivo, measurable elevation in Factor X activation was not observed using the FXP assay. We excluded the possibility that FXP is more rapidly cleared from the circulation of endotoxin-treated animals than controls. The absence of measurable increases of Factor $\mathrm{X}$ activation in endotoxemia contrasts with previous data showing that high dose recombinant Factor VIla infusions in chimpanzees produce significant increments in plasma FXP levels, followed by elevations in $F_{1+2}$ and FpA (3). In these latter experiments, the magnitude of the increase in markers for thrombin generation was similar to that observed in the present study. To explain the apparent paradox, we postulate that other mechanisms coupled with tissue factor expression are required for endotoxin-induced prothrombin activation in vivo. It has been observed that endotoxins can trigger platelet activation in vitro $(24,25)$. We have also shown that humans receiving TNF infusions have augmented platelet activation in vivo and develop mild thrombocytopenia (26). If endotoxin or TNF directly activate platelets in vivo, the catalytic efficiency of the Factor Xa generated by the functional Factor VIIa-tissue factor complex could be much enhanced in endotoxin-infused chimpanzees. However, in Factor VIIa-treated animals, prothrombin activation would occur on "unactivated" cells with a requirement for much larger quantities of Factor $\mathrm{Xa}$ to comparably activate prothrombin. It should be noted that the initial coagulation measurements were obtained 30 min after endotoxin administration, and it cannot be excluded that transient increases in Factor $\mathrm{X}$ activation could have occurred during this time interval.

We have previously administered recombinant TNF as an intravenous bolus to normal human volunteers and demonstrated significant elevations in markers of thrombin generation (8). Inhibition of the endotoxin-elicited increase in serum TNF was associated with inhibition of these elevations in markers of coagulation activation. While one can infer from in vitro data $(27,28)$ and from the present data that TNF plays a critical role in augmenting tissue factor expression in vivo, we are not able to determine whether the elaboration of TNF is absolutely required for this process, moreover since pharmaco- 
logic agents, such as pentoxyfylline, that elevate intracellular cAMP levels also directly inhibit endotoxin-induced tissue factor expression by monocytes (6). Resolution of this issue will require further studies using potent and specific inhibitors of the cytokine.

The data in chimpanzees with monoclonal antibody to tissue factor are consistent with those obtained with an $E$. coli septic shock model in baboons (10). In these experiments, the administration of a different but less potent monoclonal antibody that cross-reacts with baboon tissue factor attenuated the coagulopathy and prevented mortality. In addition, the administration of a monoclonal antibody that blocks contact system activation in this sepsis model reduced the severity of hypotension but did not ameliorate the subsequent coagulopathy (29). In the present experiments, we did not observe alterations in the plasma levels of Factor XIIa-C1 inhibitor complexes and kallikrein- $\mathrm{Cl}$ inhibitor complexes after endotoxin infusions. It cannot be excluded that slight activation of the contact system might have been missed by the assays; however, the apparent half life of disappearance of these complexes (30-50 min) (17, 30 ) indicates that significant activation would have been detected. This provides further support for the premise that the contact system does not play a significant role in coagulation mechanism activation in patients with Gram-negative septicemia.

Whereas endotoxin elicited dose-dependent increases in cytokine levels and thrombin generation, the activation of the fibrinolytic mechanism was not dose-dependent, since increments in plasminogen activator activity and PAP complexes were similar at lipopolysaccharide doses of $\geq 2 \mathrm{ng} / \mathrm{kg}$ body wt. This suggests that the coagulation and fibrinolytic systems in the animals are responding differently to endotoxin challenge. We also observed that the anti-tissue factor monoclonal antibody completely inhibited endotoxin-induced thrombin generation, but did not alter the activation of the fibrinolytic system. Thus, we conclude that the activation of fibrinolysis in the chimpanzee is not dependent on the extent of thrombin generation at the endotoxin doses used in our studies, although it cannot be excluded that very small traces of thrombin not detected by the assays for markers of thrombin generation are responsible for the activation of the fibrinolytic system. Pentoxifylline administration inhibited cytokine elaboration as well as fibrinolysis, which suggests the existence of a direct link between the elaboration of cytokines and the activation of the fibrinolytic mechanism in vivo. Indeed, it is known from in vitro studies that TNF increases the production of urokinasetype plasminogen activator (31) and plasminogen activator inhibitor type 1 (32) by human endothelial cells, which is confirmed by in vivo observations $(33,34)$. The above observations suggest that the specific blockade of tissue factor expression may be a more effective approach than pentoxifylline for the treatment or prevention of DIC in septic individuals because of distinctly different effects on the fibrinolytic responses.

The benefits of these two therapeutic approaches in patients with sepsis accompanied by DIC will ultimately need to be established by randomized clinical trials. Our studies, however, demonstrate that the chimpanzee model provides detailed information regarding the pathogenetic mechanisms in endotoxemia and can be used to evaluate other novel therapeutic interventions.

\section{Acknowledgments}

We would like to thank Richard D. Sublett and John E. Geltosky (R. W. Johnson Pharmaceutical Research Institute, San Diego, CA) for providing us with the anti-tissue factor monoclonal antibody (TF8-5G9).

This work was supported in part by a grant from the Dutch Thrombosis Foundation (90.002) and National Institutes of Health grants HL-33014 and HL-16411. Kenneth A. Bauer is an Established Investigator of the American Heart Association. Harry R. Büller and Sander van Deventer are recipients of a fellowship from the Royal Netherlands Academy of Art and Sciences. Tom van der Poll is supported by a grant from the Netherlands Organization for Scientific Research.

\section{References}

1. Michie, H. R., K. R. Manogue, D. R. Spriggs, A. Revhaug, S. O’Dwyer, C. A. Dinarello, A. Cerami, S. M. Wolff, and D. W. Wilmore. 1988. Detection of circulating tumor necrosis factor after endotoxin administration. N. Engl. J. Med. 318:1481-1486.

2. van Deventer, S. J. H., H. R. Büller, J. W. ten Cate, L. A. Aarden, C. E. Hack, and A. Sturk. 1990. Experimental endotoxemia in humans: analysis of cytokine release and coagulation, fibrinolytic, and complement pathways. Blood. 76:2520-2526.

3. ten Cate, H., K. A. Bauer, M. Levi, T. S. Edgington, R. D. Subblett, S. Barzegar, B. L. Kass, and R. D. Rosenberg. 1993. The activation of Factor IX and Factor $\mathrm{X}$ by recombinant Factor VIIa in vivo is mediated by tissue factor. J. Clin Invest. 92:1207-1212.

4. Suffredini, A. F., P. C. Harpel, and J. E. Parillo. 1989. Promotion and subsequent inhibition of plasminogen activator after administration of intravenous endotoxin to normal subjects. $N$. Engl. J. Med. 320:1165-1172.

5. Han, J., P. Thompson, and B. Beutler. 1990. Dexamethasone and pentoxifylline inhibit endotoxin-induced cachectin/tumor necrosis factor synthesis at separate points in the signaling pathway. J. Exp. Med. 172:391-394.

6. Ollivier, V., S. Houssaye, and C. Ternisien. 1993. Endotoxin-induced tissue factor mRNA in human monocytes is negatively regulated by a cyclic AMP-dependent mechanism. Blood. 81:973-979.

7. Zabel, P., M. M. Schönharting, D. T. Wolter, and U. F. Schade. 1989. Oxpentifylline in endotoxemia. Lancet. ii:1474-1477.

8. van der Poll, T., H. R. Büller, H. ten Cate, C. H. Wortel, K. A. Bauer, S. J. H. van Deventer, C. E. Hack, H. P. Sauerwein, R. D. Rosenberg, and J. W. ten Cate. 1990. Activation of coagulation after administration of tumor necrosis factor to normal subjects. New Eng. J. Med. 322:1622-1627.

9. Ruf, W., and T. S. Edgington. 1991. An anti-tissue factor monoclonal antobody which inhibits TF-VIIa complex is a potent anticoagulant in plasma. Thromb. Haemostas. 66:529-533.

10. Taylor, F. B., Jr., A. Chang, W. Ruf, J. H. Morrissey, L. Hinshaw, R. Catlett, K. Blick, and T. S. Edgington. 1991. Lethal E. coli septic shock is prevented by blocking tissue factor with monoclonal antibody. Circ. Shock. 33:127134.

11. Bauer, K. A., B. L. Kass, H. ten Cate, M. A. Bednarek, J. J. Hawiger, and R. D. Rosenberg. 1989. Detection of Factor X activation in humans. Blood. 74:2007-2015.

12. Greenwood, F. C., W. M. Hunter, and J. S. Glover. 1963. The preparation of ${ }^{131}$ I-labeled growth hormone of high specific radioactivity. Biochem. J. 89:114123.

13. Nosslin, B. 1973. Analysis of disappearance time-curves after single injection of labeled proteins. CIBA Found. Symp. 9:113-130.

14. Helle, M., E. Boeije, E. de Groot, A. de Vos, and L. Aarden. 1991. Sensitive ELISA for interleukin-6. Immunol. Methods. 138:47-52.

15. Bauer, K. A., B. L. Kass, H. ten Cate, J. J. Hawiger, and R. D. Rosenberg. 1990. Factor IX is activated in vivo by the tissue factor mechanism. Blood. 76:731-736

16. Teitel, J. M., K. A. Bauer, H. K. Lau, and R. D. Rosenberg. 1982. Studies of the prothrombin activation pathway utilizing radioimmunoassays for the $F_{1+2}$ fragment and thrombin-antithrombin complex. Blood. 59:1086-96.

17. Nuijens, J. H., C. C. M. Huijbregts, A. J. M. Eerenberg-Belmer, and C. E. Hack. 1988. Quantification of plasma Factor XIIa-C1 inhibitor and kallikrein$\mathrm{C} 1$ inhibitor complexes in sepsis. Blood. 72:1841-188.

18. Verheijen, J. H., E. Mullaart, G. T. G. Chang, C. Kluft, and G. Wijngaards. 1982. A simple spectrophotometric assay for extrinsic (tissue-type) plasminogen activator applicable to measurements in plasma. Thromb. Haemostasis. 48:266-269.

19. Levi, M., C. E. Hack, J. P. de Boer, D. P. M. Brandjes, H. R. Büller, and J. W. ten Cate. 1991. Reduction of contact activation related fibrinolytic activity 
in Factor XII deficient patients. Further evidence for the role of the contact system in fibrinolysis in vivo. J. Clin. Invest. 88:1155-1160.

20. Bevilacqua, M. P., J. S. Prober, G. R. Majeau, W. Fiers, R. S. Cotran, and M. A. Gimbrone. 1986. Recombinant tumor necrosis factor induces procoagulant activity in human vascular endothelium: characterization and comparison with the actions of interleukin 1. Proc. Natl. Acad. Sci. USA. 83:4533-4537.

21. Colucci, M., G. Balconi, R. Lorenzet, A. Pietra, and D. Locati. 1983. Cultured human endothelial cells generate tissue factor in response to endotoxin. J. Clin. Invest. 71:1893-1896.

22. Moore, K. L., S. P. Andreoli, N. L. Esmon, C. T. Esmon, and N. U. Bang. 1987. Endotoxin enhances tissue-factor and suppresses thrombomodulin expression of human vascular endothelium in vivo. J. Clin. Invest. 79:124-30.

23. Gregory, S. A., J. H. Morrissey, and T. S. Edgington. 1989. Regulation of tissue factor gene expression in the monocyte procoagulant response to endotoxin. Mol. Cell. Biol. 9:2752-2755.

24. Hawiger, J., A. Hawiger, S. Steckley, S. Timmons, and C. Cheng. 1977. Membrane changes in human platelets induced by lipopolysaccharade endotoxin. Br. J. Haematol. 35:285-299.

25. Grabarek, J., S. Timmons, and J. Hawiger. 1988. Modulation of human platelet protein kinase C by endotoxic lipid A. J. Clin. Invest. 82:964-971.

26. Bauer, K. A., H. Ten Cate, S. Barzegar, D. R. Spriggs, M. L. Sherman, and R. D. Rosenberg. 1989. Tumor necrosis factor infusions have a procoagulant effect on the hemostatic mechanism of humans. Blood. 74:165-172.

27. Nawroth, P. P., and D. M. Stern. 1986. Modulation of endothelial cell hemostatic properties by tumor necrosis factor. J. Exp. Med. 163:740-745.

28. Conway, E. M., R. Bach, R. D. Rosenberg, and W. H. Konigsberg. 1989.
Tumor necrosis factor enhances expression of tissue factor mRNA in endothelial cells. Thromb. Res. 53:231-241.

29. Pixley, R. A., R. A. DeLa Cadena, J. D. Page, N. Kaufman, E. G. Wyshock, A. Chang, F. B. Taylor, Jr., and R. W. Colman. 1993. The contact system contributes to hypotension but not disseminated intravascular coagulation in lethal bacteremia. In vivo use of a monoclonal anti-Factor XII antibody to block contact activation in baboons. J. Clin. Invest. 92:61-68.

30. de Smet, B. J. G. L., J. P. de Boer, J. Agterberg, G. Rigter, W. K. Bleeker, and C. E. Hack. 1993. Clearance of human native, proteinase-complexed and proteolytically inactivated $\mathrm{Cl}$ inhibitor in rats. Blood. 81:56-61.

31. van Hinsbergh, V. W. M., T. Kooistra, E. A. van den Berg, H. M. G. Princen, W. Fiers, and J. J. Emeis. 1988. Tumor necrosis factor increases the production of plasminogen activator inhibitor in human endothelial cells in vitro and in rats in vivo. Blood. 72:1467-1473.

32. Schleef, R. R., M. P. Bevilacqua, M. Sadwey, M. A. Gimbrone, Jr., and D. J. Loskutoff. 1988. Cytokine activation of vascular endothelium. Effects on tissue-type plasminogen activator and type 1 plasminogen activator inhibitor. $J$. Biol. Chem. 263:5797-5803.

33. van Hinsbergh, V. W. M., K. A. Bauer, T. Kooistra, C. Kluft, G. Dooijewaard, M. L. Sherman, and W. Nieuwenhuizen. 1990. Progress of fibrinolysis during tumor necrosis factor infusions in humans. Concomitant increase in tissue-type plasminogen activator, plasminogen activator inhibitor type 1 , and fibrin(ogen) degradation products. Blood. 76:2284-2289.

34. van der Poll, T., M. Levi, H. R. Büller, S. J. H. van Deventer, J. P. de Boer, C. E. Hack, and J. W. ten Cate. 1991. Fibrinolytic response to tumor necrosis factor in healthy subjects. J. Exp. Med. 174:729-732. 